\title{
ETHICAL ISSUES IN ROBOT-ASSISTED PLAY FOR CHILDREN WITH SPECIAL NEEDS
}

\author{
KERSTIN DAUTENHAHN \\ University of Waterloo, Canada
}

Robot-assisted therapy for children with autism has become increasingly widespread over the past 20 years. Currently most major robotics laboratories worldwide have a project on this topic, and many encouraging results have been published. My own research team has investigated this area since the late 1990s, using different robotic platforms, ranging from machine-like to zoomorphic and humanoid robots. In a number of studies, we focused on specific therapeutic or educational goals, but a key part has been the encouragement of play, and the need to include other people, apart from the child with autism, in the interaction with robot -grounding mechanical/robotic interaction in human experience and meaning. Thus, the robot adopts the role of a social mediator. My talk will discuss some of the ethical challenges involved in the design and conduct of this research, discussing different levels of potential benefits for the children, and different roles robots can play in teaching children with special needs in general, and children with autism in particular, about communication and interaction skills. 